variety of subjects.

Although the volume gives only a selection and does not cover all the areas of current interest in astrophysics - there is no chapter on quasar absorption lines, for example - students will find it an excellent resource to stimulate their discovery of a rich and exciting field.

The influence of Bahcall can be felt throughout the book, and not only in an editorial sense. Beyond his own direct contributions to many fields in astrophysics (including solar neutrinos on which he provides an article), many authors here attest to the impact he has had in encouraging those around him to choose fundamental problems, to bear in mind the observational consequences of theoretical speculations, to push theoretical consequences to their limits, and to apply advanced analytical and statistical tools. Many visitors to the Institute for Advanced Study have encountered the high standards of excellence set by Bahcall during Friday "stuffy lunch" presentations.

Wendy Freedman is at the Carnegie

Observatories, 813 Santa Barbara Street,

Pasadena, California 91101, USA.

\section{Science and salvation}

\section{Redeeming Culture: American Religion in an Age of Science}

by James Gilbert

University of Chicago Press: 1997. Pp. 390. $\$ 28.95$

\section{George Marsden}

Early in the twentieth century, sociologists predicted that, with the growth of science and technology, traditional religion would decline. In the United States that has not happened (see Nature 386, 435; 1997). Rather, science and technology flourish alongside every variety of religion, from traditional to New Age. The group suicide of the Heaven's Gate on-line space-age cult is just the latest reminder that almost any sort of scientific-religious combination can emerge in that fertile environment. Even among academics, natural scientists in America are more likely to be traditionally religious than are humanists.

James Gilbert's Redeeming Culture provides some fascinating background for understanding the interactions of science and religion in the United States. Starting with the Scopes trial of 1925, which shaped an image of antagonism between science and biblicist Christianity, Gilbert describes about a dozen major encounters between American science and religion, mostly from the era just after the Second World War. His account is admittedly episodic, rather than systematic, but it does provide intriguing pictures of some of the highlights in this cultural exchange, not only among intellectuals, but also at the popular level.

One especially revealing incident is how in the early 1950s the US Air Force regularly offered its troops Moody Bible Institute science films such as God of Creation and God of the Atom as part of their moral training. Another is the immense mainstream publicity and then controversy surrounding Immanuel Velikovsky's bestselling Worlds in Collision which alleged that a crash of a comet into Mars helped to validate events in the Hebrew scriptures such as the Sun standing still. Gilbert also recounts popular efforts to relate science and religion, as in the films of Frank Capra or at the Seattle World's Fair of 1962.

Although Gilbert does not argue any strong thesis about the overall significance of these episodes, they do suggest that the cultural status of discussions of science and religion were very different half a century ago than today. In 1947, just after Western civilization had narrowly escaped collapse during the horrors of the Second World War, cultural leaders were engaged in intense discussion about how to re-establish civilization on a firmer basis. Religion and science were the old and the new authorities and the crying need of the hour seemed to be to reconcile the two. "Redeeming culture" is an apt title for the enterprise.

In the United States, science was at the height of its prestige. Yet the atom bomb tarnished the scientific image and the nation was also in the midst of a religious revival. How could an adequate moral basis be found for rebuilding the civilization? Many intellectuals thought that religion would be necessary for that, perhaps religion updated in the light of science. Others saw science itself as the only hope for establishing universal values.

It is particularly striking from the perspective of half a century later that so many cultural leaders believed that it would be possible to find a foundational set of values for the whole culture, or at least for its mainstream. Today, 'pluralism' and 'diversity' are the principal motifs in thinking about culture, and the idea that there could be one dominant way of reconciling science and religion seems quaint. Although there still are many intellectual and popular efforts to relate science to religion, most take place within particular religious traditions and few presume to speak for the entire cultural mainstream.

In the era after the Second World War it was still common to talk about reconciling 'science and religion' as though these designated essentially only two points of view. In fact, 'religion' included many irreconcilable divisions, including many differ- ences among Christians themselves. Some of Gilbert's episodes illustrate this. He describes the early decades of the American Scientific Affiliation, founded by conservative Protestants in 1941, which eventually tried to carve out territory between creation scientists on the right and liberal Christians and secularists on the left. In the meantime, representatives of the liberal Protestant establishment at Harvard founded the Institute on Religion in an Age of Science, which had wider ambitions to establish a culture-wide scientific religion. Even though both these organizations had grown out of the American Protestant mainstream, they had opposing views of the essence of their Christian heritage.

Gilbert suggests that the various science and religion dialogues help to explain the persistence of religious faith in the United States, as such exchanges helped to create cultural space for religion. That is probably correct. Yet, if that is the significance of the stories, then comparison is called for. Were the US discussions of religion and science after the war much different from those in the United Kingdom, the Netherlands, Germany or Scandinavia? I suspect that they were much the same at the intellectual level, but that the main difference was the much larger role that evangelical Protestant and other forms of popular religion played in the United States.

By the late 1960s, the mainstream science and religion dialogues of the midcentury were swept aside by cultural forces over which such efforts had little influence. Science declined in cultural prestige. Mainstream Protestantism declined even faster. Yet in the United States evangelicalism as well as popular New Age religions were waiting in the wings. These offered so many varieties of ways of reconciling, or not reconciling, science and religion that it is hard to see how that factor could be the critical variable.

Nonetheless, Gilbert does point out that virtually every group has to negotiate between these cultural authorities and he skilfully provides some valuable background for reflecting on the multiform American ways of doing so.

George Marsden is in the Department of History, University of Notre Dame, Notre Dame,

Indiana 46556, USA.

A revised and expanded edition of No Other Gods: On Science and American Social Thought by Charles E. Rosenberg has just been published. First issued in 1976, this influential book looks at the ways in which social institutions and values have shaped American scientific practice and thought. Rosenberg, a historian of medicine, now extends the discussion to address the current debate about the social construction of knowledge. Johns Hopkins University Press,

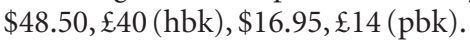

